\title{
Toxoplasmosis: A Review on its Public Health Importance
}

\author{
Praveen Kumar Praveen ${ }^{1}$, Subha Ganguly ${ }^{2}$, Parveez Ahmad Para ${ }^{3}$, Shivchand Yadav ${ }^{4}$ \\ and Kinkar Kumar ${ }^{5}$ \\ ${ }^{1}$ Assistant Professor, Department of Veterinary Public Health \& Epidemiology, \\ ${ }^{2 *}$ Associate Professor, Department of Veterinary Microbiology, \\ ${ }^{3}$ Assistant Professor, Department of Livestock Products Technology, \\ ${ }^{4}$ Assistant Professor, Department of Veterinary Anatomy \& Histology, ARAWALI VETERINARY \\ COLLEGE (Affiliated with Rajasthan University of Veterinary and Animal Sciences, Bikaner), \\ Rajasthan, India; \\ ${ }^{5}$ Subject Matter Specialist, Krishi Vigyan Kendra, Pupari, Sitamarhi, Bihar, India
}

\begin{abstract}
Toxoplasmosis is a parasitic disease caused by Toxoplasma gondii. Infections with toxoplasmosis usually cause no symptoms in adult humans. It is characterized in humans by a few weeks or months of mild flulike illness such as muscle aches and tender lymph nodes. In some cases, ocular complications may also develop. The mild symptoms may progress to seizures and in coordination in movements in patients with weaker immune response. The condition of congenital toxoplasmosis proves fatal for carrying mothers during pregnancy.
\end{abstract}

Keywords: Parasite, Toxoplasmosis, Zoonosis.

\section{INTRODUCTION}

It is a widely prevalent zoonotic disease caused by a protozoan parasite. Toxoplasma gondii, which occurs intracellularly in various tissues or cells of the host. [1]

\section{LIFE CYCLE: [2]}

Life cycle of the parasite is either direct or indirect.

In cats or wild feline, Mountain lion, Leopard cat and Bob cat, which are the final host, the parasite undergoes an enteroepithelial cycle of development as in Coccidia and the life cycle would be completed without involving any host.

However, a range of warm blooded animals including birds, rodents, marsupials, domestic and wild mammals and man act as intermediate host and in these the parasite multiplies asexually in tissues cells(extraintestinal cycle). In the final host extraintestinal cycle can occur simultaneously with enteroepithelial development.[3-5]

\subsection{Enteroepithelial Cycle}

This is induced in cat and other felines by:

1. Ingestion of meat of intermediate host containing cysts and pseudocysts or,

2. Ingestion of sporulated oocysts which are voided in the faeces of infected felines. Parasites enter epithelial cells of intestine and multiply by schizogony which leads to gametogony. The oocysts are finally voided in the faeces. The prepatent period is $3-11$ days and pick oocysts excretion in $5-20$ DPI, vary depending on the stage of parasite inducing the infection.[3]

\subsection{Extraintestinal Cycle}

These cycles are also induced by ingestion of either cysts, pseudocysts or oocysts. The parasites enters a variety of tissue cells i.e. cells of reticuloendothelial system, myocardium, liver fibroblast etc and multiplies intracellularly by a form of fission(endodyogeny) to produce $8-16$ parasites. The host cell which assumes the shape of pseudocysts, bursts and the parasites enter into other cells. These forms of 
parasites which are crescent shaped resembling merozoites of coccidian multiplied in similar manner and hence called tachyzoites. This development is generally associated with acute visceral stage of disease.[6-8]

\section{Human TOXOPLASMOSIS[9-11]}

Human toxoplasmosis is of two types:

1. Congenital

2. Acquired, depending on mode of infection

\subsection{Congenital Toxoplasmosis}

It occurs in children if pregnant mother suffers from primary infection or act as carrier of chronic infection. The cysts in latter cases may revert to tachyzoites cycle under pregnancy stress or cortisone therapy and infect the fetuses. Mother might remain symptomless. Transmission occurs during late pregnancy. In severe cases there is abortion and organisms can be detected in all aborted materials. If the child is born alive it shows fever, adenopathy, spleenomegaly, hepatomegaly, hydrocephalus, microcephaly, psychomotodisturbances, choroidoretinitis and cerebral calcification are also seen. Delayed manifestations of congenital toxoplasmosis in children are congenital contact choroidoretinitis, anaemia and serious mental retardation. In mild cases the symptoms are few and difficult to recognize.

\subsection{Acquired Toxoplasmosis}

It remains asymptomatic in $25 \%$ of cases. The disease is severe particularly in the immunosuppressed persons. Symptoms may vary from mild fever and body pain to fatal encephalitis. Fever, lymphocytosis, eye lesions of doughtful origin, abortion, obstrcuctive history, myocarditis and meningioencephalitis are some of the common manifestations.

The incidence of toxoplasmosis in man judged by seroprevalence is high. It was reported $90 \%$ in France, $80 \%$ in Britain and 60\% in USA. In India $75-80 \%$ adults are seropositive. However 100 of 1000 are mild clinical cases go unnoticed and used for Influenza or Pyrexia of unknown origin.

\section{Diagnosis in Man ANd Animals[12-15]}

Various techniques employed for diagnosis are:

i. Isolation through mouse inoculation

ii. Demonstration of parasite/parasite antigen and tissue by histopathology, and by ELISA

iii. Demonstration of antibodies by Sabin Feldman dye test, CFT, Modified direct agglutination test and ELISA.

iv. Detection of parasite in tissue DNA by using PCR technique.

\section{TREatMent}

i. Sulfadiazene is effective on intestinal stages in cats.

ii. Clindamycin is effective against both acute and chronic.

\section{Prevention and Control}

i. Direct and Indirect contact with cat should be avoided particularly by pregnant women and young girl.

ii. Stray cat should be eliminated

iii. Meat and Vegetable should be thoroughly cooked

iv. Drinking water should be of clean source

v. Meat should not be included in feed of food animals 


\section{REFERENCES}

[1] Hunter, C.A. and Sibley, L.D. (November 2012). Modulation of innate immunity by Toxoplasma gondii virulence effectors. Nature Reviews Microbiology. 10 (11): 76678. doi:10.1038/nrmicro2858. PMID 23070557.

[2] Flegr, J., Prandota, J., Sovičková, M. and Israili, Z.H. (March 2014). Toxoplasmosis- a global threat. Correlation of latent toxoplasmosis with specific disease burden in a set of 88 countries. PLoS ONE. 9 (3): e90203.doi:10.1371/journal.pone.0090203

[3] Torgerson, P.R. and Mastroiacovo, P. (1 July 2013). The global burden of congenital toxoplasmosis: a systematic review. Bulletin of the World Health Organization, 91 (7): 5018. doi:10.2471/blt.12.111732

[4] Ferguson, D.J. (2009). Toxoplasma gondii: 1908-2008, homage to Nicolle, Manceaux and Splendore. Memórias Do Instituto Oswaldo Cruz, 104 (2): 133-48. doi:10.1590/S007402762009000200003.PMID 19430635

[5] CD, Christian, D.A. and Hunter, C.A. (2012). Immune response and immunopathology during toxoplasmosis. Seminars in Immunopathology, 34 (6): 793-813.doi:10.1007/s00281-012-0339-3

[6] Dubey, J.P. and Jones. J.L. (September 2008). Toxoplasma gondii infection in humans and animals in the United States. International Journal for Parasitology, 38(11): $1257-$ 78. doi:10.1016/j.ijpara.2008.03.007

[7] Jones, J.L., Kruszon-Moran, D., Wilson, M., McQuillan, G., Navin, T. and McAuley, J.B. (2001). Toxoplasma gondii infection in the United States: seroprevalence and risk factors. American Journal of Epidemiology, 154 (4): 357-65.doi:10.1093/aje/154.4.357

[8] Paul, M. (1 July 1999). Immunoglobulin G Avidity in Diagnosis of Toxoplasmic Lymphadenopathy and Ocular Toxoplasmosis. Clin. Diagn. Lab. Immunol., 6 (4): 514 8. PMC 95718 . PMID 10391853.

[9] Dubey, J.P., Hodgin, E.C. and Hamir, A.N. (2006). Acute fatal toxoplasmosis in squirrels (Sciurus carolensis) with bradyzoites in visceral tissues. The Journal of Parasitology. 92 (3): 658-9. doi:10.1645/GE-749R.1

[10] Blanchard, N., Dunay, I.R. and Schlüter, D. (2015). Persistence of Toxoplasma gondii in the central nervous system: a fine-tuned balance between the parasite, the brain and the immune system. Parasite Immunol., 37 (3): 150-158. doi:10.1111/pim.12173.

[11] Parlog, A., Schlüter, D. and Dunay, I.R. (March 2015). Toxoplasma gondii-induced neuronal alterations. Parasite Immunol., 37 (3): 159-170.

[12] Pappas, G., Roussos, N. and Falagas, M.E. (October 2009). Toxoplasmosis snapshots: global status of Toxoplasma gondii seroprevalence and implications for pregnancy and congenital toxoplasmosis. International Journal for Parasitology, 39 (12): 138594.doi:10.1016/j.ijpara.2009.04.003

[13] Cook, T.B., Brenner, L.A., Cloninger, C.R., et al. (2015). Latent infection with Toxoplasma gondii: association with trait aggression and impulsivity in healthy adults. J. Psychiatr. Res., 60: 87-94.doi:10.1016/j.jpsychires.2014.09.019

[14] Hurley, R.A. and Taber, K.H. (2012). Latent Toxoplasmosis gondii: emerging evidence for influences on neuropsychiatric disorders. J Neuropsychiatry Clin Neurosci., 24 (4): 37683.doi:10.1176/appi.neuropsych.12100234

[15] Barakat, A.M., Salem, L.M., El-Newishy, A.M., Shaapan, R.M. and El-Mahllawy, E.K. (2012). Zoonotic chicken toxoplasmosis in some Egyptians governorates. Pakistan Journal of Biological Sciences: PJBS, 15 (17): 821-6.doi:10.3923/pjbs.2012.821.826 